\section{Counting the numbers}

SIR - I was shocked to read that Nature is to devalue the billion in line with American usage (358, 2; 1992). After all, not everybody who reads a copy of an article will have read this article too. $\mathrm{He}$ also has to remember that you made up your mind on 2 July 1992. Instead of increasing the confusion with this decision, it would perhaps be better to find an unambiguous way of citing such figures: The decimal prefixes are excellent tools for this purpose. If you use $\mathrm{M}=$ mega for $10^{6}, \mathrm{G}=$ giga for $10^{9}$, and $\mathrm{T}=$ tera for $10^{12}$ you find that $\$ 5 G$ is quite distinct from \$5T. You could even use $P$ $=$ peta for $10^{15}$ or $\mathrm{E}=$ exa for $10^{18}$ knowing that you are acting according to the international standard ISO 1000 and that there is no room for misunderstanding. These decimal prefixes are also useful in tables when the range for figures is sometimes very extended.

Martin A. Lobeck

Auf der Stippe 19,

D-5222 Morsbach-Hülstart, Germany

SIR - So Nature has abandoned the English use of billion $\left(10^{12}\right)$ in favour of the American use $\left(10^{9}\right)$. I find the excuse to be rather feeble: “. . . it has been difficult to dragoon correspondents into describing, say, the US federal deficit as 'close on $\$ 500,000$ million' . . ." Whoever tried to dragoon them into that was mistaken: the correspondents should have been dragooned into describing it

\section{P. J. A. Howard}

\section{G. Manitius}

3700 Rønna, D. P. Hansell

30 The Ridgeway, as 'close on $\$ 500$ milliard'.

Ashrigg, Ashmount Road,

Grange-over-Sands,

Cumbria LA11 6BX, UK

SIR - I was born in Europe and lived many years in America. As American mathematicians and scientists use the terms million $10^{6}$ and billion $10^{9}$, I (a drop in the ocean) am prepared to accept it. I was taught at school that million is $10^{6}$, billion $10^{12}$, trillion $10^{18}$, and the numbers in between are called milliard $10^{9}$, billiard $10^{15}$.

Sct.Pedersgade 2A,

Bornholm, Denmark

SIR - Why should not a scientific journal use the SI prefixes? Megabuck is already in colloquial use and a new precision might be indicated by the use of megadollar and so on. The only disadvantage is that the teradollar might be heard to refer to 'dollar imperialism'.

Tonbridge, Kent TN10 4NH, UK

$\square$ The usage (which Nature has now abandoned) that 1 billion $=10^{12}$ was part of the formal recommendation of the Conference Générale des Poids et Measures in 1948. - Editor, Nature.

\section{Building a low-cost space station}

SIR - Last year, many in the US science community united in opposition to space station Freedom and argued that its enormous cost of $\$ 30$ billion would not produce an adequate scientific return. After an extended and highly charged debate, Congress agreed to continue its funding. This year, budgetary difficulties are mounting and Congress is engaged in another debate. Not included in the discussion so far is an alternative space station design proposed to the National Aeronautics and Space Administration last year, which would cost less and entail fewer risks than the existing shuttle system ${ }^{1}$

The proposed space station, which we call STS-Lab, consists of two main elements from the existing shuttle: a modified orbiter (Orbiter-II) and a modified external tank (ET). All the re-entry and landing flight systems are removed from Orbiter-II including the wings, tail, thermal protection tiles, landing gear and avionics, reducing the 180,000 pound weight by 40,000 pounds.

The Orbiter-II cargo bay contains a NATURE · VOL 358 • 30 JULY 1992

for Freedom and a crew rescue vehicle could be accommodated by attachment to these docking ports.

We estimate that STS-Lab can be built for $\$ 3$ billion within four years. It would be placed in orbit in a single unmanned launch; our cost estimates assume the conversion of Columbia, modification of an existing ET and use of an existing Freedom laboratory module. The STSLab design and the cost and schedule estimates were developed by a group of experienced aerospace engineers.

In general, there are no significant differences in the research that could be supported by Freedom compared with STS-Lab. The same types and amount of scientific experiments could be conducted in either of the orbiting laboratories. However, STS-Lab's large ET volume would allow laboratory space to be easily expanded.

Budgetary support for all categories of science is being threatened by Freedom. As scientists we must do all we can to ensure that the debate in Congress includes serious discussion of practical alternatives.

\section{Randolph H. Ware}

University Navstar Consortium,

PO Box 3000 ,

Boulder, Colorado 80307, USA

\section{Ware, R. H. \& Culbertson, P. E. J. pract. Appl. Space} 3, 17-23 (1992)

2. Garriott, O. K. J. pract. Appl. Space 3, 25-32 (1992).

\section{How rare is rare?}

SIR - It is commonly said that fraud in science is rare. What is truly rare is to find some objective statement of what the word "rare" means in the context of fraud. In a letter to ASM News (August 1991, p. 391) I reported on a survey of 24 scientific colleagues which suggested that to them "rare" means that "the instances of deliberate fraud in basic research" would be no greater that 1 in 10,000 publications. Now, in an article (Nature 357, 427; 1992) on a fabricated paper from the National Institutes of Health, you quote Michael Green of the University of Massachusetts as suggesting that the instances of fraudulent manuscripts may actually be as low as 1 in 100,000 . I would repeat in ironic form the challenge I made in my previous letter: can anyone making claims published in a scientific journal about the rarity of fraud in science show us their data?

Inwin Tessman

Department of Biological Sciences,

Purdue University,

West Lafayette,

Indiana 47907, USA

\section{Take 100 lines}

SIR - Daedalus ${ }^{1}$ does not seem to have done his homework. The technique he describes is the well known 'Lempel-ZivWelch' data compression algorithm ${ }^{2,3}$. Perhaps this is an example of morphic resonance?

\section{A. P. R. Cooper}

British Antarctic Survey, High Cross, Madingley Road,

Cambridge CB3 OET, UK

1. Nature 358, 22 (1992).

2. Nelson, M. Dr Dobbs J. 156, 29-36 (1989).

3. Ziv, J. \& Lempel, A. I.E.E.E. Transactions on Information Theory (May 1977) 